\title{
Cross-sectional area variations of internal jugular veins during supine head rotation in multiple sclerosis patients with chronic cerebrospinal venous insufficiency: a prospective diagnostic controlled study with duplex ultrasound investigation
}

Massimiliano Farina ${ }^{1 *}$, Eugenio Novelli ${ }^{2}$ and Raffaello Pagani ${ }^{3}$

\begin{abstract}
Background: Normally, chronic cerebrospinal venous insufficiency (CCSVI) has been studied using echo-colour Doppler (ECD). Subjects are examined in the supine and sitting positions, in accordance with a static protocol without rotation of the head. A dynamic approach, to assess venous sizes with different degrees of head rotation, has only been performed to improve jugular venous catheterisation. These echographic studies have suggested that head rotation to the contralateral side increases the cross-sectional area (CSA) of the internal jugular veins (IJVS) in supine subjects. Our goal was to evaluate the behaviour of CSA of the IJVs during supine head rotation in multiple sclerosis (MS) patients with CCSVI, compared to healthy controls (HCs).
\end{abstract}

Methods: The IJVs of 313 MS patients with CCSVI (male 43.8\%, male/female 137/176; mean age 45 years old, range 19-77 years) and $298 \mathrm{HCs}$, matched by gender (male 43.6\%, male/female 130/168) and age (mean age 46 years old, range 20-79 years), were compared using ECD. Their CSAs were evaluated with the subjects seated in a tiltable chair, first in the supine position at the level of the cricoid cartilage, with the head in a neutral position, and then after contralateral rotation to $90^{\circ}$ from midline.

Results: Significant differences between the jugular CSAs before and after head rotation were observed only in the MS patients for the IJVs with wall collapse $(F[6,1215]=6414.57, p<0.001)$, showing on longitudinal scans a typical "hourglass" aspect that we defined as "miopragic". No significant difference was found in the distribution of these miopragic veins with regard to MS duration. There was a strong association between the CCSVI scores and the complexity of jugular morphological types $\left(X^{2}[9, N=313]=75.183, p<0.001\right)$. Wall miopragia was mainly observed in MS patients with SP (59.3\%) and PP (70.0\%) clinical forms, compared to RR (48.3\%) forms $(p=0.015)$.

Conclusion: A dynamic ECD approach allowed us to detect IJVs with a significant increase in their CSAs during head rotation, but only in MS subjects. This feature, most likely the expression of congenital wall miopragia, could be secondary to dysregulation of collagen synthesis, but further histochemical studies will be needed to confirm this hypothesis.

Keywords: CCSVI, MS, Jugular wall miopragia, Hourglass appearance, SCM stretching manoeuvre, Balloon angioplasty, Type I/III collagen

\footnotetext{
* Correspondence: massimiliano.farina@centrostudipatologievenolinfatiche.it

'Phlebolymphology Diseases Centre, Monza Polyclinic, Monza, Italy

Full list of author information is available at the end of the article
} 


\section{Background}

Chronic cerebrospinal venous insufficiency (CCSVI) is a congenital syndrome affecting the extracranial vessels (internal jugular and azygos veins) that is characterised by different valve malformations, stenoses and segmental or global hypoplasia with impaired venous drainage, opening collateral circulation [1-3]. Several studies have demonstrated a strong association between multiple sclerosis (MS) and CCSVI, but subsequent clinical research has failed to support this hypothesis [4-13]. Thus, the debate currently continues over whether the relationship is real. In fact, some reports have claimed that the data in the literature have been insufficient to establish the importance of CCSVI as a major factor in MS pathogenesis. Echo-colour Doppler (ECD) studies of CCSVI are usually performed according to the five Zamboni criteria; the detection of at least two of these parameters indicates a diagnosis of CCSVI. Nevertheless, ECD investigation is still not currently standardised in many respects, and it is overly dependent on individual patients and operators, with high interobserver variability for untrained examiners $[14,15]$. However, different studies have reported that ECD is more sensitive than the magnetic resonance venography (MRV) in detecting intraluminal jugular defects, while MRV is more sensitive in showing collaterals $[9,16]$. Both techniques have proved effective in assessing the size and course of venous vessels of the neck, showing internal jugular vein (IJV) asymmetry in both normal subjects and MS patients. The left internal jugular vein is usually smaller than the right due to preferential intracranial venous drainage through one sigmoid sinus versus the other, with weak correlations with age and gender [17-21]. Venous size can vary depending on hydration status, position, cardiac status, thoracic pump, head position, and compression from adjacent structures [22-26]. Even dysfunction of the cardiovascular autonomic nervous system can reduce vascular tone, affecting jugular size [27]. More frequently, MS patients have shown a jugular cross-sectional area (CSA) $\leq 30 \mathrm{~mm}^{2}$ compared to healthy controls (HCs) $(43.5 \%$ vs. 16.7\%) [28]. These ultrasonographic findings were also confirmed by catheter venography $(\mathrm{CV})$ and were mainly detected in the middle part of the IJV, at the level of the cricoid cartilage immediately below the sternocleidomastoid muscle (SCM) [29]. They have not been clearly correlated with intraluminal defects, although they have been explained by low values of internal pressure [30]. At this level, CV and ECD have shown a collapsed jugular vein with loss of its elliptical appearance under SCM imprinting [5,29]. Patients have usually been examined in the supine and sitting positions, in accordance with a static protocol without head rotation ( $0^{\circ}$ from midline). A dynamic approach to assess venous sizes with different degrees of head rotation has only been applied to improve jugular venous catheterisation. These echographic studies have suggested that head rotation to the contralateral side increases the CSA of IJVs in supine subjects [25,31]. The aim of this study was to evaluate the behaviour of the CSA of the IJVs during supine head rotation in MS patients with CCSVI, compared to HCs.

\section{Methods}

\section{Patients and controls}

Between June 2010 and November 2012, we studied 313 patients with clinically defined MS (according to the 2010 revised McDonald diagnostic criteria) and CCSVI, who were diagnosed with the presence of at least two of the five Zamboni criteria [1,32]. This group consisted of 172 patients with the relapsing-remitting (RR) clinical form, 91 with the secondary progressive (SP) form and 50 with the primary progressive (PP) form. An MS specialist evaluated all the patients, assigning disability scores according to the Kurtzke scale (EDSS). Table 1 shows the related demographic and clinical characteristics. We also studied 298 volunteers HCs (students and technical and administrative staff from our hospital) with a mean weight of $70.23 \mathrm{~kg}$ (standard deviation [SD] = 7.97; range: 43-98), who were matched by gender (male $43.6 \%$, male/female 130/168) and age (mean age 46 years old, range 20-79 years). Physical and neurological examinations were performed on the controls. We excluded from the study any subject with previous head or neck surgery, neck swellings, severe heart disease, serious kidney and liver diseases, thrombosis of the jugular vein (s), jugular vein catheterisation, vasculitis, Behçet's syndrome, collagen diseases, congenital cerebral malformations and congenital vascular malformations. The Ethical

Table 1 Demographic and clinical characteristics of MS patients with CCSVI

\begin{tabular}{|c|c|c|c|c|}
\hline & $\begin{array}{l}\text { Whole MS } \\
(\mathrm{N}=313)\end{array}$ & $\begin{array}{l}\text { RR form } \\
(\mathrm{N}=172)\end{array}$ & $\begin{array}{l}\text { SP form } \\
(N=91)\end{array}$ & $\begin{array}{l}\text { PP form } \\
(N=50)\end{array}$ \\
\hline Age (years) (Mean [range]) & $45(19-77)$ & $39(19-69)$ & $50(32-77)$ & $54(21-76)$ \\
\hline Gender (\% male -n male/female) & $43.8(137 / 176)$ & $40.1(69 / 103)$ & $43.9(40 / 51)$ & $56(28 / 22)$ \\
\hline Body weight $(\mathrm{kg})$ (Mean \pm SD) (range) & $67.47 \pm 7.12(49-88)$ & $67.40 \pm 6.55(51-84)$ & $67.49 \pm 7.54(49-82)$ & $67.68 \pm 8.28(52-88)$ \\
\hline EDSS (Mean [range]) & $3.5(1-9)$ & $3.0(1-8)$ & $5.0(2-9)$ & $4.0(1-8)$ \\
\hline Disease duration (years) (Mean [range]) & $11(1-40)$ & $7(1-30)$ & $15(1-38)$ & $14(1-40)$ \\
\hline
\end{tabular}


Committee of the Local Health Authority, Monza Brianza, Italy, approved this prospective, diagnostic, controlled study, and all the participants provided written informed consent.

\section{Duplex ultrasound investigation Classic approach}

The classic approach was applied as proposed in 2011, according to the revised protocol by an expert panel of the International Society for Neurovascular Disease (ISNVD) [33]. A single experienced vascular sonographer performed all the investigations in the morning, with the subjects first placed in the supine position $\left(0^{\circ}\right)$ and then in the upright sitting $\left(90^{\circ}\right)$ position. An ECD system (MyLabVinco, Esaote SpA, Florence, Italy), equipped with a linear array transducer probe with an operating bandwidth of 3-11 MHz (B-modes frequencies, 3.5 - 5.0 - 6.6 - $10.0 \mathrm{MHz}$; Doppler frequencies, 3.3 $5.0 \mathrm{MHz}$ ) for extracranial scans, was used. The transcranial approach was performed with a phased array transducer probe with an operating bandwidth of $1-4 \mathrm{MHz}$ (B-modes frequencies, 2.0 - 2.5 - 3.3 MHz; Doppler frequencies, 1.6 $2.0-2.5 \mathrm{MHz}$ ). The vascular sonographer was particularly experienced with venous disease and had performed approximately 10,000 ultrasound investigations per year over the past few years. Each subject underwent an examination of laterocervical area of the neck, exploring both the internal jugular and vertebral veins. We also evaluated deep cerebral veins from the transcondylar window. Longitudinal supine scans of the IJVs were obtained from the distal part (J3) above the carotid bifurcation to the subclavian junction (J1), passing through the intermediate portion at the level of the cricoid cartilage (J2). All the scans were recorded for subsequent reconstruction and morphological analysis. The longitudinal diameters were measured at the levels of J1, J2 and J3. Measurements of the cross-sectional area (CSA $-\mathrm{mm}^{2}$ ) of the IJVs were obtained in real-time at the same point (J2), by placing the transducer probe over the apex of the clavicle-sternocleidomastoid triangle at the level of the cricoid cartilage and perpendicular to the skin. For the computations, we used an ellipsoid or continuous trace method, referring to the greatest ellipse at the end-expiratory phase. Each supine measurement (longitudinal diameters and CSAs) was repeated three times, and the average of the three measurements was used for comparison. These basal assessments were performed with the subject's head in a neutral position $\left(0^{\circ}\right.$ midline $)$, which was defined as having the subject's sagittal plane perpendicular to the supporting surface. In the supine position, a small pillow ( $8 \mathrm{~cm}$ height) was placed under the subject's head to induce a greater degree of relaxation of the neck musculature [34]. On the examined skin, we used a large amount of gel to assure perfect coupling of the transducer, to reduce excessive pressure, and to avoid changing the IJV shape and dimension. During the position changes, each subject was kept in a resting condition (no voluntary muscle movements and contractions) as much as possible, using a proper electromechanical tiltable chair. Adequate fluid intake was maintained during the 24 hours preceding the survey (500 $\mathrm{ml}$ upon waking before the exam) to avoid dehydration, which can affect morphological detection of the IJVs.

\section{Dynamic approach: the sternocleidomastoid muscle- stretching manoeuvre}

After basal evaluations, each supine subject underwent a dynamic manoeuvre that consisted of contralateral rotation of the head to $90^{\circ}$ from midline compared to the scanned side, with the chin slightly raised (Figure 1). In this manner, we obtained the elongation and thinning of the SCM, with external pressure reduction on the middle portion of the jugular vein and a related increase in the venous section, as reported in normal subjects by several authors in studies to optimise central venous cannulation [20,25]. At the same level, we also obtained a second measurement of the CSA of the IJVs during the end-expiratory phase. This measurement was the result of the average of three consecutive detections. Subsequently, we calculated the difference between the mean values of the jugular CSAs in both positions $(\triangle C S A)$, by subtracting the area obtained in the neutral position from that obtained in maximum contralateral rotation.

\section{IJV morphological types}

A careful analysis of the literature allowed for the identification of three different morphological types of IJVs: normal veins; veins with only VDs; and hypoplastic vein

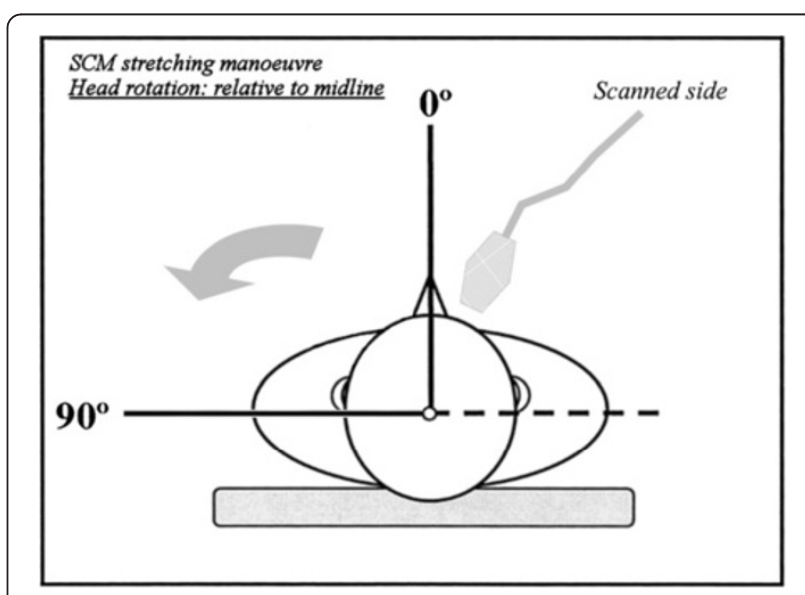

Figure 1 Maximum contralateral head rotation compared to the scanned side. 
(small veins). The reconstruction of the longitudinal ultrasound scans of the IJVs provided a better definition and understanding of these morphological types. A normal jugular vein gradually reduces its longitudinal diameter passing from $\mathrm{J} 3$ to $\mathrm{J} 1$, as described in several texts on human anatomy [35] and as recently confirmed by CT [36] and ultrasound studies [19,20]. Therefore, the vein presents a typical "telescopic" appearance (Figure 2). More recently, studies involving MS patients have revealed the presence of IJVs with intraluminal defects, such as proximal malformed valves and septa webs (Figure 3) [1,4,5]. A hypoplastic jugular vein is much smaller. A recent CT study [36] defined as hypoplastic those IJVs with proximal longitudinal anteroposterior diameters (J1) two SDs less than the mean $(\leq 5.45 \mathrm{~mm})$. With regard to the area, these veins showed a CSA $\leq 30 \mathrm{~mm}^{2}$ [33]. In these forms, the vessels appear to be "cylindrical", with the diameter broadly across the entire length (Figure 4).

\section{Statistical analysis}

Continuous variables are described as means and standard deviations (SDs), while counts and percentages are used to describe qualitative variables. A frequency matching approach for gender and age was applied in this study. On the basis of the distribution quartiles, four classes of disease duration $(<5,5-10,11-16,>16$ years $)$ were used to test the hypothesis that miopragia is congenital. Differences in $\triangle \mathrm{CSA}$ measurements, before/after the manoeuvre in patients and controls, among the IJV morphological types are reported with means \pm SDs and were analysed using a one-way analysis of variance (per IJV analysis).

The association between the complexity of the IJV morphological types of the patients and their CCSVI scores was tested using $X^{2}$ statistics (per patient analysis). Kruskal-Wallis one-way analysis of variance was used to determine the explanatory power of the new diagnostic classification of IJV malformations in CCSVI scoring and to test whether the CCSVI score differed among the groups of patients, which were based on IJV morphological types. Post-hoc pairwise comparisons after Kruskal-Wallis analysis were performed with the Mann-Whitney $U$ test and with $p$-values adjusted for multiple comparisons, which were performed using the Holm-Bonferroni method. The statistical analyses were performed using SPSS software (version 14.0, SPSS Inc., Chicago, IL, USA). All 2-tailed p-values less than 0.05 were considered statistically significant.

\section{Results}

A total of 1,222 IJVs were evaluated: 596 in the $\mathrm{HCs}$ group and 626 in the MS group. Table 2 shows the distribution of the five Zamboni criteria in the two groups. As reported in the literature, our reconstruction of the longitudinal ultrasound scans of IJVs in MS patients detected normal veins $(11.7 \%)$, veins with only VDs (49.2\%) and hypoplastic veins (7.5\%). We also identified two new morphological types of IJVs, which we defined as "miopragic" (27.1\%) and "miopragic with VDs” (4.5\%). A miopragic jugular vein has a typical aspect of an "hourglass", with an extremely small diameter

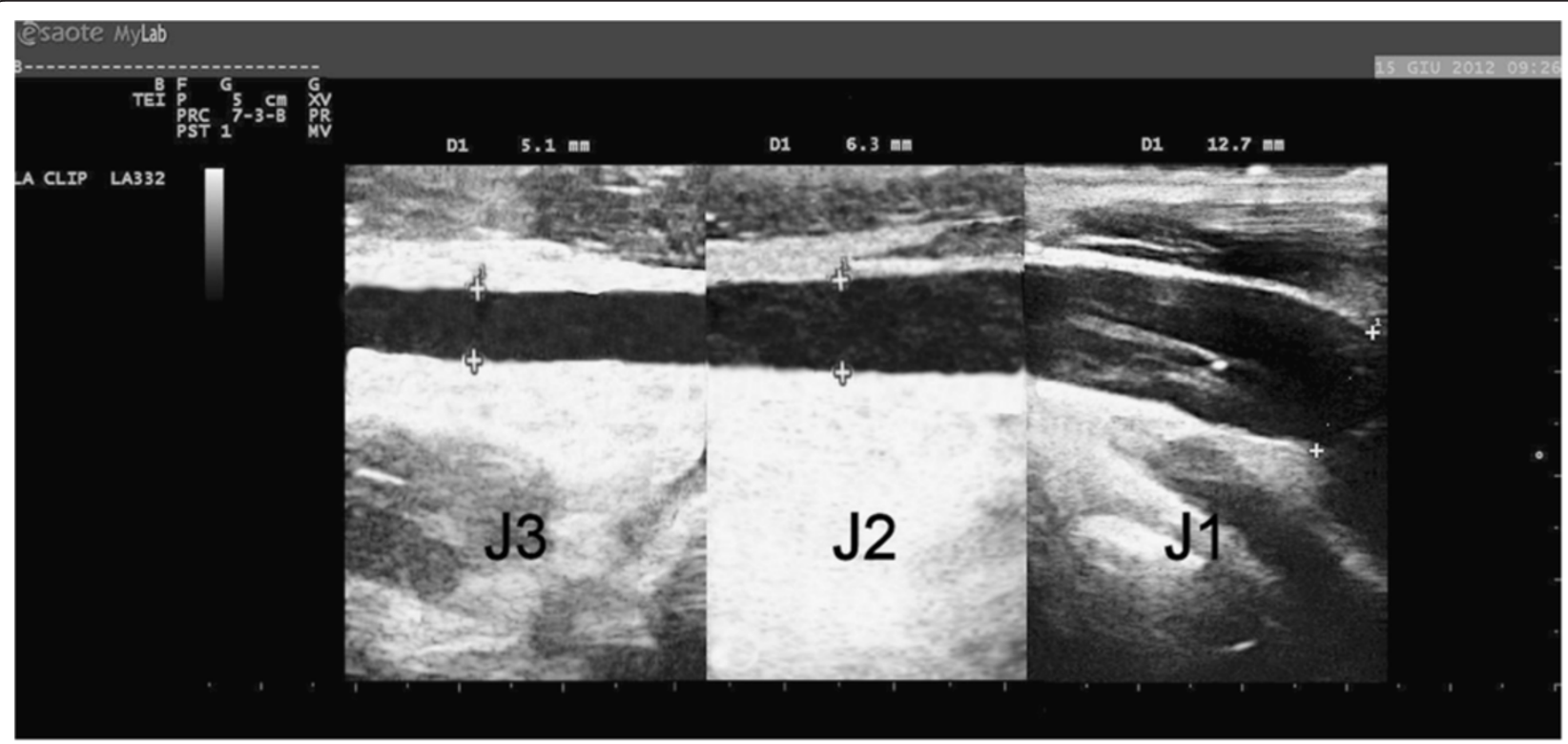

Figure 2 A normal IJV. Progressive reduction of the vessel diameter proceeding from J1 point (12.7 mm) to J3 (5.1 mm) and passing through J2 $(6.3 \mathrm{~mm})$ 


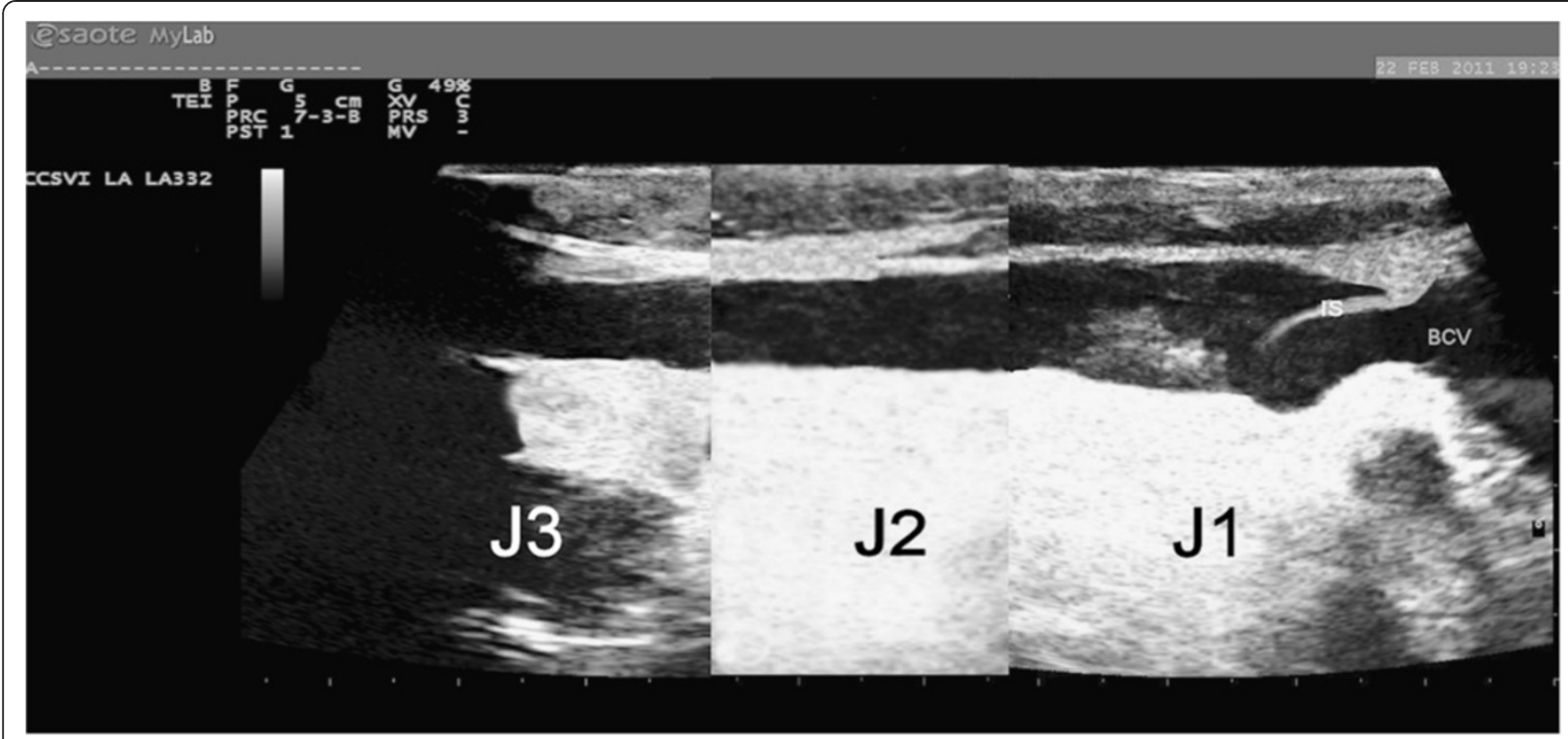

Figure 3 Proximal (J1) valve malformation (inverted septum). BCV = brachiocephalic vein.

in the intermediate portion (mean $\pm \mathrm{SD}=3.0 \pm 0.8 \mathrm{~mm}$ ) and larger values at the $\mathrm{J} 1(10.5 \pm 1.0 \mathrm{~mm})$ and $\mathrm{J} 3$ levels $(5.3 \pm 0.6 \mathrm{~mm}$ ) (Figure 5). In $4.5 \%$ of cases, miopragic veins presented with proximal VDs and mean diameter values that were comparable to previous types $(J 1=10.2 \pm$ $1.1 \mathrm{~mm}$; J2 = $3.3 \pm 0.7 \mathrm{~mm}$; J3 = $5.2 \pm 0.5 \mathrm{~mm}$ ) (Figure 6) The HCs showed normal jugular veins and proximal VDs in $93.5 \%$ and $6.5 \%$ of cases, respectively. In addition, we detected no miopragic or hypoplastic types in this subject group. Table 3 clearly describes these results, and as shown, the differences in frequency of IJV morphological types between the patients and controls were highly significant $\left(X^{2}[4, \mathrm{~N}=1222]=825.129, \mathrm{p}<0.001\right)$. In a per IJV analysis, we compared the $\triangle$ CSA measurements after head rotation in the MS patients and $\mathrm{HCs}$, with regard to their IJV morphological types. Significant differences between jugular CSAs before and after the reported manoeuvre were only observed in the MS patients $(F[6,1215]=6414.57, \mathrm{p}<0.001)$. The results are summarised in Table 4 and Figure 7 . In a per patient

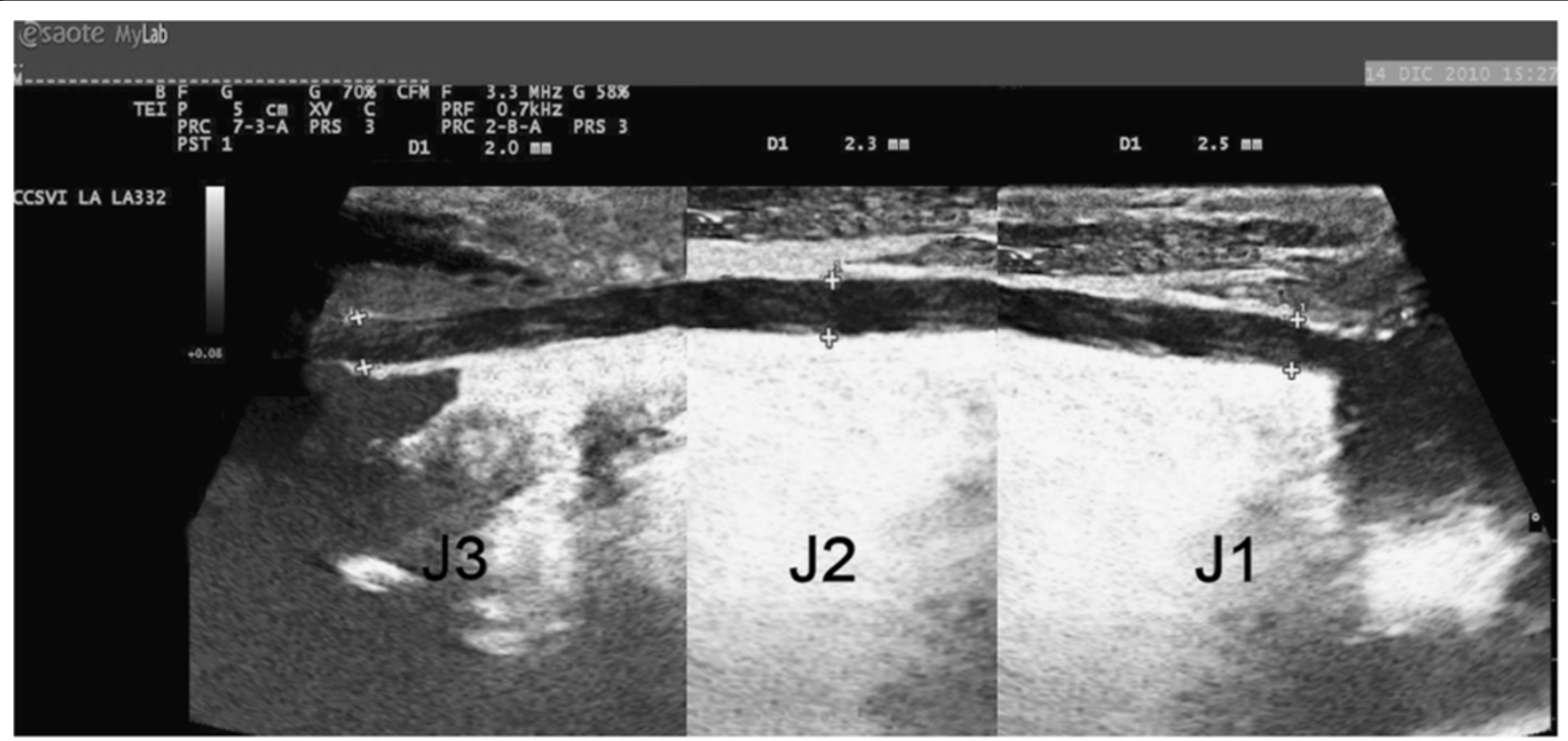

Figure 4 An hypoplastic IJV (cylindrical appearance). The diameter (between 2.0 and $2.5 \mathrm{~mm}$ ) is broadly similar for all lengths. 
Table 2 Five Zamboni criteria distributed in both subject groups

\begin{tabular}{|c|c|c|c|c|c|}
\hline Colour Doppler criteria & $\begin{array}{c}\text { Relapsing } \\
\text { remitting } \\
(\mathrm{N}, \%) \\
\end{array}$ & $\begin{array}{c}\text { Secondary } \\
\text { progressive } \\
(\mathrm{N}, \%)\end{array}$ & $\begin{array}{c}\text { Primary } \\
\text { progressive } \\
(\mathrm{N}, \%)\end{array}$ & $\begin{array}{c}\text { Whole MS } \\
(\mathrm{N}, \%) \\
\end{array}$ & $\begin{array}{c}\text { Healthy } \\
\text { controls } \\
(\mathrm{N}, \%) \\
\end{array}$ \\
\hline \multirow{2}{*}{$\begin{array}{l}\text { 1. Reflux in IJVs and/or Ws with the head at } 0^{\circ} \text { and }+90^{\circ} \\
\text { or reflux in one position with blocked flow in the other }\end{array}$} & $91 / 313$ & $58 / 313$ & $29 / 313$ & $178 / 313$ & $18 / 298$ \\
\hline & $29.1 \%$ & $18.5 \%$ & $9.3 \%$ & $56.9 \%$ & $6.0 \%$ \\
\hline \multirow[t]{2}{*}{ 2. Reflux in the deep cerebral veins } & $162 / 313$ & $88 / 313$ & $49 / 313$ & 299/313 & $64 / 298$ \\
\hline & $51.8 \%$ & $22.1 \%$ & $15.6 \%$ & $95.5 \%$ & $21.5 \%$ \\
\hline \multirow{2}{*}{$\begin{array}{l}\text { 3. High resolution B-mode evidence of proximal } \\
\text { IJV malformations }\end{array}$} & $162 / 313$ & $90 / 313$ & $42 / 313$ & $294 / 313$ & $39 / 298$ \\
\hline & $51.8 \%$ & $28.8 \%$ & $13.3 \%$ & $93.9 \%$ & $13.1 \%$ \\
\hline \multirow{2}{*}{$\begin{array}{l}\text { 4. Flow not Doppler detectable in the IJV and/or W } \\
\text { at } 0^{\circ} \text { and } 90^{\circ}\end{array}$} & $22 / 313$ & $28 / 313$ & $18 / 313$ & $68 / 313$ & $0 / 298$ \\
\hline & $7.0 \%$ & $8.9 \%$ & $5.7 \%$ & $21.7 \%$ & $0 \%$ \\
\hline \multirow[t]{2}{*}{ 5. $\Delta C S A$ in the IJV $\leq 0$} & $20 / 313$ & $29 / 313$ & $13 / 313$ & $62 / 313$ & $0 / 298$ \\
\hline & $6.4 \%$ & $9.3 \%$ & $4.1 \%$ & $19.8 \%$ & $0 \%$ \\
\hline
\end{tabular}

analysis, we also correlated the IJV morphological types with the CCSVI scores (Table 5). A strong association was observed between the IJV morphological types and the CCSVI scores $\left(X^{2}[9, \mathrm{~N}=313]=75.183, \mathrm{p}<0.001\right)$. In fact, the patients with isolated VDs had a median CCSVI score of two, those with hypoplasia plus VDs or miopragia plus VDs had a median score of three, and the patients with hypoplasia of an IJV and miopragia plus VDs of the other IJV had a median score of four. The above-mentioned classification of the complexity of the patients' IJV morphological types was able to explain the variability of CCSVI scores in the MS group. In our series, we reported a statistically significant difference in the mean ranks of CCSVI scores among the different morphological types of IJVs (Kruskal-Wallis $\mathrm{H}[3]=48.094, \mathrm{p}<0.001$ ). The mean rank was 110.60 for isolated VDs, 153.59 for hypoplasia plus VDs, 177.93 for miopragia plus VDs and 219.43 for patients with hypoplasia of an IJV and miopragia plus VDs of the other IJV. Table 6 shows post-hoc paired comparisons of CCSVI scores among the IJV morphological types after Kruskal-Wallis analysis. The patients with hypoplasia + miopragia + VDs had higher CCSVI scores than patients with hypoplasia + VDs $\left(\mathrm{H}_{3}\right.$ hypothesis, $\left.\mathrm{p}=0.033\right)$, while the patients with hypoplasia + VDs had higher CCSVI scores than patients with only VDs $\left(\mathrm{H}_{4}\right.$ hypothesis, $\mathrm{p}=0.024)$. Likewise, the patients with miopragia + VDs had higher CCSVI scores than patients with only VDs $\left(\mathrm{H}_{5}\right.$ hypothesis, $\left.\mathrm{p}<0.001\right)$, and the patients with hypoplasia + miopragia + VDs had higher CCSVI scores than patients with only VDs $\left(\mathrm{H}_{6}\right.$ hypothesis, $\left.\mathrm{p}<0.001\right)$. Wall

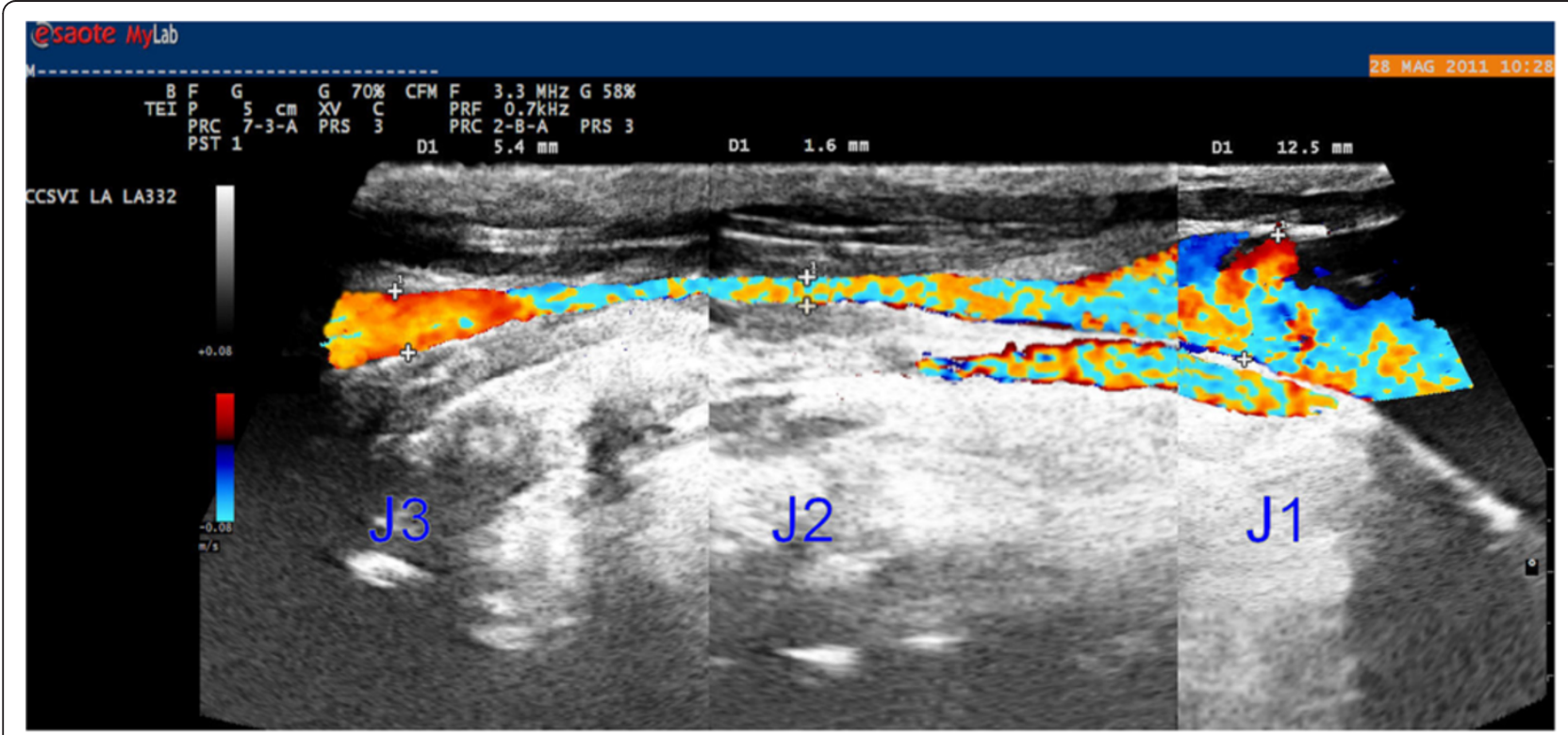

Figure 5 IJV with wall miopragia (hourglass appearance). Narrowing of the middle segment (J2 - $1.6 \mathrm{~mm}$ ) with larger values at each end (12.5 and $5.4 \mathrm{~mm}$ at $\mathrm{J} 1$ and $\mathrm{J} 3$ points, respectively). 


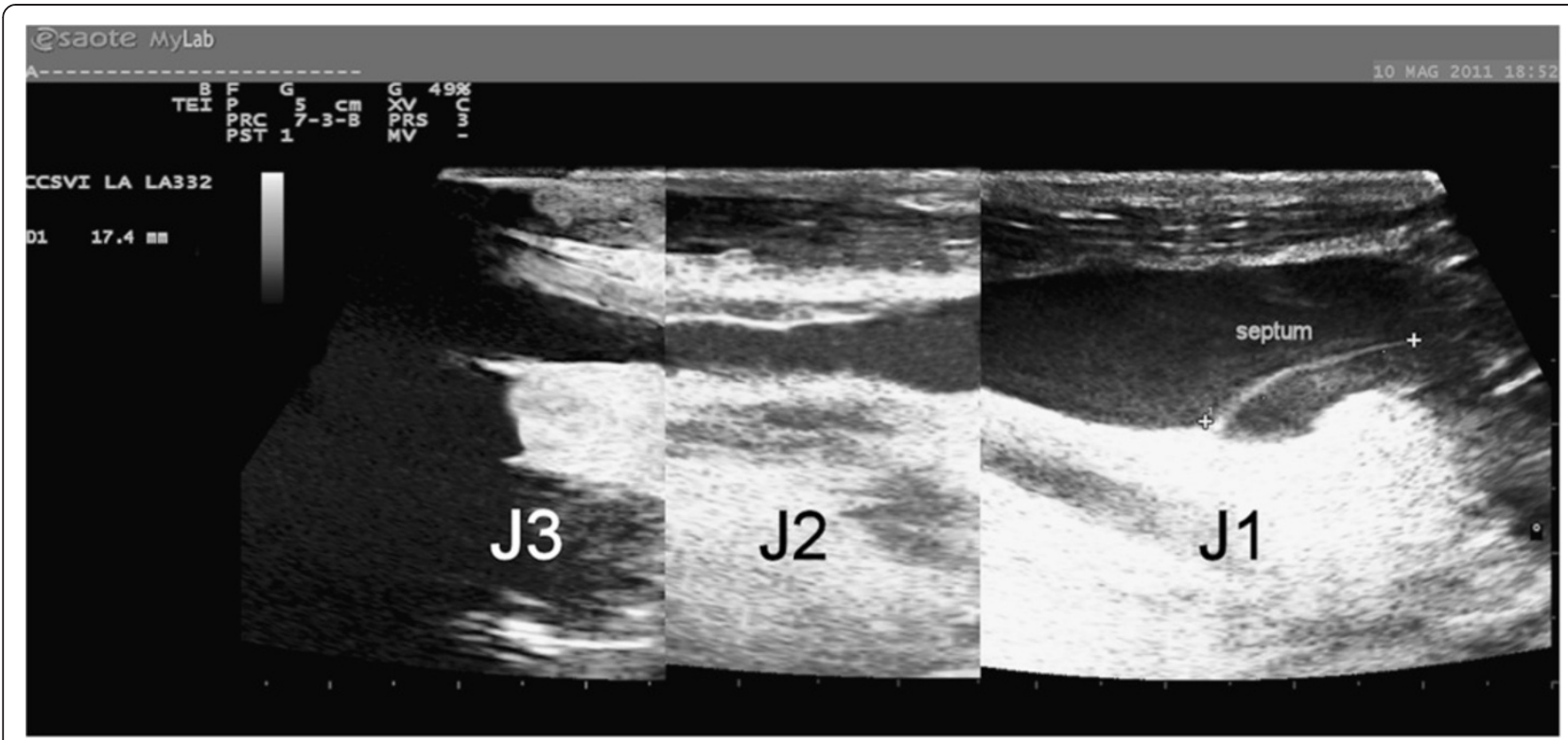

Figure 6 A miopragic IJV with proximal valve malformation (posterior septum).

miopragia was mainly observed in MS patients with the PP (70.0\%) and SP (59.3\%) clinical forms compared to the RR $(48.3 \%)$ form $(p=0.015)$. In contrast, no significant differences in the observed frequencies of wall miopragia were noted among the four classes of disease duration (56.0\%, 58.0\%, 45.3\%, 60.6\%; $\mathrm{p}=0.260$ ); this result did not change even after distinguishing for clinical forms.

\section{Discussion}

Currently, there is much ECD evidence regarding the presence of proximal jugular valve malformations with altered local flow in MS patients with different prevalence data according to the authors $[1,7,15,37]$. In our experience we have found CCSVI in $89.8 \%$ of MS patients and in $5.4 \%$ of HCs. Similar results have been obtained with other diagnostic imaging techniques, such as MRV [9,38,39] and CV [8,37]. However, all diagnostic methods have technical issues, and not all are completely standardised $[9,14]$. Since 2009, jugular abnormalities have been included in the Consensus Document of the International Union of Phlebology (IUP) on venous malformations and have been classified as congenital

Table 3 Distribution of IJV morphological types in both subject groups (per IJV analysis, $N=1222$ )

\begin{tabular}{lcc}
\hline & MS patients with CCSVI & Healthy controls \\
\hline 1. Normal & $73 / 62611.7 \%$ & $557 / 59693.5 \%$ \\
2. Only VDs & $308 / 62649.2 \%$ & $39 / 5966.5 \%$ \\
3. Hypoplasia & $47 / 6267.5 \%$ & $0 / 5960 \%$ \\
4. Miopragia & $170 / 62627.1 \%$ & $0 / 5960 \%$ \\
5. Miopragia + VDs & $28 / 6264.5 \%$ & $0 / 5960 \%$ \\
\hline
\end{tabular}

truncular lesions [40], but until now, little was known regarding their histopathogenesis. The recent work of Coen was the only study that addressed the issue from this point of view, and it was the first that detected an altered ratio of type I/III collagen in the IJVs of MS patients, without any differences in cellularity or connective tissue distribution [41]. This condition has been similarly described in many other apparently unrelated conditions (e.g., varicose saphenous veins, haemorrhoids, paraoesophageal hernia, skin incisional hernia, recurring inguinal hernia, pelvic organ prolapse), suggesting connective tissue systemic involvement [42-44]. These structural changes were also found in vessel wall samples taken far from balloon angioplasty treatment areas, suggesting their independence on local trauma. As evidenced by several studies, type I collagen provides mainly tensile strength and rigidity by building thick fibre that offer resistance to tissue, while type III collagen determines elasticity [43]. These histochemical data could explain the typical hourglass appearance of a part of the IJVs that we defined as "miopragic". This morphological type was only detected in MS patients in the supine neutral position, with related flow blocked in their middle portions. It could be the result of vein collapse under SCM pressure because of reduced wall stiffness (wall miopragia). In fact, in the resting position, muscle pressure is greater at the J2 level, where the SCM is larger and closer to the IJV, crossing it to pass medially. Here, the vein is usually positioned anterolateral to the carotid artery [45]. Similarly, external pressure (exerted on the vein) is less in the distal segment (J3), where the SCM is located lateral to the vessel, and also in the 
Table 4 Cross-sectional area variations $(\triangle C S A)$ of IJVs after head rotations (per IJV analysis, $N=1222$ )

\begin{tabular}{|c|c|c|c|c|c|c|c|c|}
\hline \multirow[b]{2}{*}{$\begin{array}{l}\text { IJV morphological } \\
\text { types }\end{array}$} & \multirow[b]{2}{*}{$\mathrm{N}$} & \multicolumn{2}{|c|}{$\begin{array}{l}\text { Right or left CSA }\left(\mathrm{mm}^{2}\right) \\
(\text { Mean } \pm \text { SD) }\end{array}$} & \multirow[t]{2}{*}{$\begin{array}{l}\Delta C S A\left(\mathrm{~mm}^{2}\right) \\
(\text { Mean } \pm \mathrm{SD})\end{array}$} & \multirow[b]{2}{*}{$\mathrm{N}$} & \multicolumn{2}{|c|}{$\begin{array}{c}\text { Right and left CSA }\left(\mathrm{mm}^{2}\right) \\
(\text { Mean } \pm \text { SD) }\end{array}$} & \multirow[t]{2}{*}{$\begin{array}{l}\Delta \mathrm{CSA}\left(\mathrm{mm}^{2}\right) \\
(\text { Mean } \pm \mathrm{SD})\end{array}$} \\
\hline & & $\begin{array}{l}\text { Neutral position } \\
\left(0^{\circ}-\text { midline }\right)\end{array}$ & $\begin{array}{c}\text { Max. rotation } \\
\left(90^{\circ} \text { from midline }\right)\end{array}$ & & & $\begin{array}{c}\text { Neutral position } \\
\left(0^{\circ}-\text { midline }\right)\end{array}$ & $\begin{array}{c}\text { Max. rotation } \\
\left(90^{\circ} \text { from midline }\right)\end{array}$ & \\
\hline Normal & 73 & $69.685 \pm 8.763$ & $74.395 \pm 9.052$ & $4.710 \pm 1.987$ & 557 & $70.084 \pm 9.098$ & $74.613 \pm 9.067$ & $4.529 \pm 1.675$ \\
\hline Only VDs & 308 & $71.050 \pm 8.876$ & $75.461 \pm 8.746$ & $4.411 \pm 2.079$ & 39 & $71.431 \pm 7.943$ & $76.374 \pm 8.549$ & $4.944 \pm 1.168$ \\
\hline Miopragic & 170 & $9.921 \pm 2.554$ & $72.695 \pm 8.413$ & $62.775 \pm 8.940\left(^{*}\right)$ & 0 & - & - & - \\
\hline Miopragic + VDs & 28 & $8.682 \pm 1.647$ & $74.400 \pm 6.483$ & $65.718 \pm 7.070\left(^{*}\right)$ & 0 & - & - & - \\
\hline \multirow[t]{2}{*}{ Hypoplastic } & 47 & $9.096 \pm 2.443$ & $11.132 \pm 2.414$ & $2.036 \pm 0.844$ & 0 & - & - & - \\
\hline & \multicolumn{4}{|c|}{ MS patients with CCSVI } & \multicolumn{4}{|c|}{ Healthy Controls } \\
\hline
\end{tabular}

${ }^{*} p<0.001$.

proximal portion (J1), where the jugular passes among the sternal and clavicular heads of the same muscle (Figure 8). In addition, the regular outflow along the IJV ensures its patency at the J3 level, with a shunt through the common facial vein towards the external or anterior jugular veins. The inferior thyroid veins mainly support J1 outflow. Contralateral rotation of the head restores regular flow along the vein through the significant increase $(F[6,1215]=$ 6414.57, $\mathrm{p}<0.001)$ in CSA in the intermediate section, which was only observed for this morphological type (see Additional files 1, 2 and 3) and was never detected in the HCs. This result in the HCs agrees with what Lorchirachoonkul and Suarez found in normal subjects, namely a non-significant increase in jugular
CSAs and longitudinal diameters with contralateral rotation of the head $[19,25]$. However, the jugular collapse could also be an expression of cardiovascular autonomic disorders, as described in MS patients by several authors $[27,46]$. A dysregulation of vegetative function would reduce venous tone, causing jugular wall collapse under SCM pressure. However, this datum is controversial because older studies, as well as recent publications, have observed no anomalies on orthostatic tests $[47,48]$. According to other researchers, autonomic disorders are present in up to $23 \%$ of MS patients [49], and this finding would not explain the jugular collapse that we found in a greater number of subjects (54.9\%). Among other findings, our data revealed no statistically significant difference in

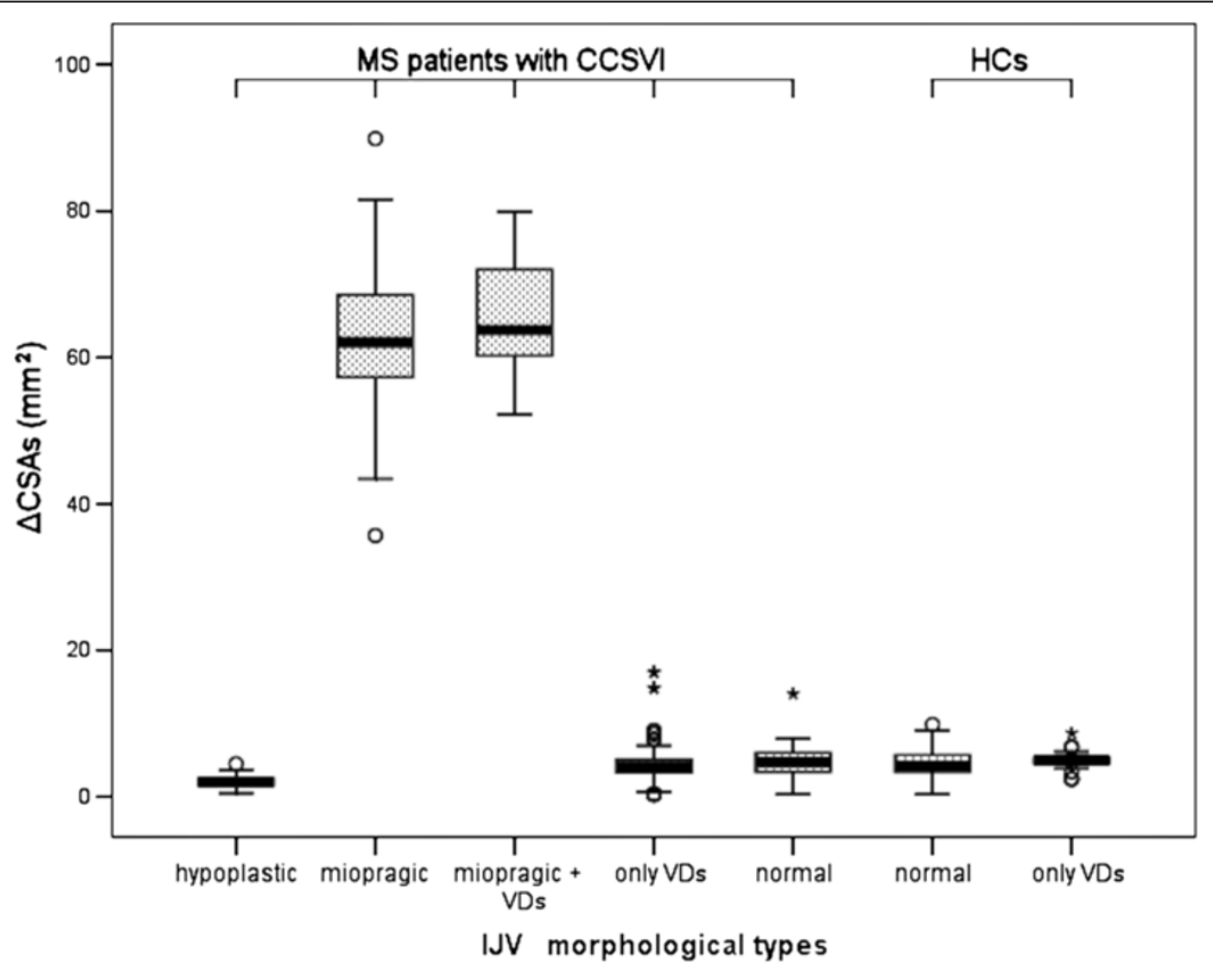

Figure 7 The $\triangle$ CSA measurements after head rotation in MS patients and HCs. Differences with respect to their IJV morphological types (per IJV analysis). 
Table 5 Distribution of IJV morphological types related to CCSVI score (per patient analysis, $\mathrm{N}=313$ )

\begin{tabular}{lcccc}
\hline & \multicolumn{4}{c}{ CCSVI score } \\
\cline { 2 - 5 } & $\mathbf{2}$ & $\mathbf{3}$ & $\mathbf{4}$ & $\mathbf{5}$ \\
& $\mathbf{( N ,} \%)$ & $\mathbf{( N ,} \%)$ & $\mathbf{( N ,} \%)$ & $\mathbf{( N ,} \%)$ \\
\hline 1. Only VDs & $58 / 94$ & $28 / 94$ & $8 / 94$ & $0 / 94$ \\
& $61.7 \%$ & $29.8 \%$ & $8.5 \%$ & $0 \%$ \\
2. Hypoplasia + VDs & $11 / 33$ & $17 / 33$ & $5 / 33$ & $0 / 33$ \\
3. Miopragia + VDs & $33.3 \%$ & $51.5 \%$ & $15.2 \%$ & $0 \%$ \\
& $34 / 172$ & $103 / 172$ & $24 / 172$ & $11 / 172$ \\
4. Hypoplasia + Miopragia + VDs & $2 / 14$ & $4 / 14$ & $8 / 14$ & $0 / 14$ \\
& $14.8 \%$ & $59.9 \%$ & $14.0 \%$ & $6.4 \%$ \\
\hline
\end{tabular}

the mean CSA of normal IJVs between MS subjects with CCSVI and HCs in the supine position, as shown in another study [28]. Similarly, the distribution of mean values of the CSA of normal jugular veins in HCs in the supine position corresponded to what has been reported by several authors $[25,28,50]$, with a trend toward an increase when passing from J3 to J1 $[20,24]$ and with rotation of the head $[19,25]$. Table 7 summarises these results, and as shown, our values of CSA are similar to those of other researchers, while they differ from those of Zamboni's two studies. We believe that our higher values might be due to the younger mean age and likely lower body weight of the participants in the Zamboni's study, compared to our and other studies. In fact, as proved by Mortensen, the internal jugular size has the best positive correlation with body weight [21]. As reported in a recent work, the failure of jugular angioplasty in one MS patient with CCSVI showed a totally collapsed middle part of the vein [26]. Surgical decompression of an atypical omohyoid muscle successfully solved this case. Others have described the omohyoid muscle as involved in the physiologic dilatation of the IJVs during opening of the mouth and deep inspiration, through short segmentary compression of the proximal part of the vein (J1) near the tendinous intersection [51]. This physiological status could become pathological in cases of prolonged compression, as detected in the lower part of the neck, or in the presence of a shorter omohyoid directly merged with the sternohyoid muscle. Patra instead was not able to locate precisely the position of the omohyoid muscle and to measure the jugular surface below it because of poor muscle echogenicity [52]. However, anatomic variations in the inferior belly of the omohyoid muscle have been rare, seen in only $3 \%$ of autopsy findings [53]. In our study, all extrinsic jugular compressions occurred in the middle part (J2) of the vein below the SCM and were therefore not attributable to the omohyoid muscle action. When investigating MS patients using MRV, some authors have found extrinsic severe stenoses in $22 \%$ of the patients' IJVs [16]. These findings indicate that CCSVI is mainly caused by valvular malformations $[1,37]$ and that extrinsic compression by a muscle could represent a less frequent nonvalvular cause of compromised cerebral venous outflow [26,54]. We believe that jugular collapse, secondary to extrinsic muscular compression, is the expression of a congenital weakness of vessel walls, likely because of a dysregulation of collagen synthesis. We support our assertions with the presence of miopragic jugular veins (combined with VDs) in $54.9 \%$ of MS patients and the absence of them in the $\mathrm{HCs}$, for whom a low percentage of VD (6.5\%) was detected instead. Therefore, if jugular valve defects can also be recognised in $\mathrm{HCs}$, wall miopragia would seem to be an exclusive feature of MS patients. If we add to this percentage the $10.5 \%$ of patients with hypoplastic jugular veins and the $4.5 \%$ of patients with combined malformations (hypoplasia + miopragia + VDs), the total value of MS patients with wall miopragia and VDs reaches 69.9\%, compared with $30.1 \%$ of those with VDs only. These data assume greater importance, given the close correlation of vein

Table 6 Post-hoc paired comparisons after Kruskal-Wallis analysis

\begin{tabular}{|c|c|c|c|}
\hline Hypothesis & $\begin{array}{l}\text { Observed } \\
\text { p-value }\end{array}$ & $\begin{array}{l}\text { Holm threshold } \\
\text { value }\end{array}$ & $\begin{array}{l}\text { Holm adjusted } p \text {-value } \\
=\max \left\{6 p_{6}, 5 p_{5}, 4 p_{4}, 3 p_{3}, 2 p_{2}, p_{1} ; k p_{k}\right\} \\
k=1,2,3,4,5,6\end{array}$ \\
\hline$\overline{\mathrm{H}_{1}}$ & 0.102 & stop & $0.102=\max (0,0,0.024,0.033,0.070,0.102)$ \\
\hline $\mathrm{H}_{2}$ & 0.035 & $0.05 / 2=0.025$ & $0.070=\max (0,0,0.024,0.033,0.070)$ \\
\hline $\mathrm{H}_{3}$ & 0.011 & $0.05 / 3=0.017$ & $0.033^{\wedge}=\max (0,0,0.024,0.033)$ \\
\hline $\mathrm{H}_{4}$ & 0.006 & $0.05 / 4=0.013$ & $0.024 \wedge=\max (0,0,0.024)$ \\
\hline $\mathrm{H}_{5}$ & 0.000 & $0.05 / 5=0.010$ & $0.000 \wedge=\max (0,0)$ \\
\hline $\mathrm{H}_{6}$ & 0.000 & $0.05 / 6=0.008$ & $0.000^{\wedge}=\max (0)$ \\
\hline
\end{tabular}

$\mathrm{H}_{1}$ : Hypoplasia+VDs vs. Miopragia+VDs, $\mathrm{H}_{2}$ : Miopragia+VDs vs. Hypoplasia+Miopragia+VDs.

$\mathrm{H}_{3}$ : Hypoplasia+VDs vs. Hypoplasia+Miopragia+VDs, $\mathrm{H}_{4}$ : Hypoplasia+VDs vs. VDs, $\mathrm{H}_{5}$ : Miopragia+VDs vs. VDs.

$\mathrm{H}_{6}$ : Hypoplasia+Miopragia+VDs vs. VDs. The hypotheses have been sorted in descending order of the observed $\mathrm{p}$-values.

$\wedge$ : statistically significant result. 


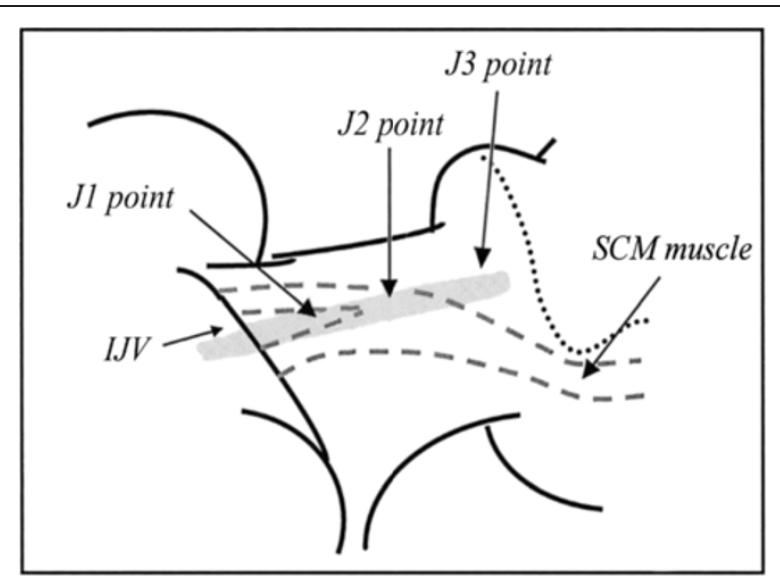

Figure 8 Anatomical relationships between SCM and IJV segments.

miopragia to the degree of haemodynamic impairment of cerebrospinal efferent vessels. In fact, as noted in our per patient analysis, jugular miopragia was mainly correlated with medium to severe scores (3-4) for CCSVI, while patients with isolated VDs show lower scores (2). Similarly, combined malformations are correlated with higher CCSVI scores. We stated that wall miopragia would not affect the totality of MS patients because in our study, we found jugular veins with isolated VDs in $30 \%$ of subjects, but this number could be higher than reported. In fact, the collagen distribution might not be the same from one patient to another or even between different segments of the same vein; therefore, we could have jugular vessels with altered collagen but not sufficiently altered to induce wall collapse. These veins would appear as normal vessels with isolated VDs. Moreover, our data demonstrated a greater prevalence of jugular wall miopragia in patients with the PP and SP clinical forms, compared to the RR form $(\mathrm{p}=0.015)$, and no significant relationship between jugular wall miopragia and MS duration, supporting the hypothesis that this morphological type is congenital. The principal limit of this study was the inability to confirm our hypothesis of jugular wall miopragia by means of a direct histochemical analysis of the vessels.

\section{Conclusions}

The reconstruction of longitudinal echographic scans of IJVs provides a full view of vessels, thereby enabling the identification of a new morphological type with an hourglass appearance, which was not detected in the HCs. This type of vein shows a unique behaviour with the SCM stretching manoeuvre, most likely because of a condition of wall miopragia, the congenital nature of

Table 7 Cross-sectional areas (CSAs) and anteroposterior (AP) diameters of IJVs in supine normal subjects with head in neutral position and after rotation

\begin{tabular}{|c|c|c|c|c|c|c|c|c|}
\hline \multirow{2}{*}{$\begin{array}{l}\text { Internal Jugular Veins (IJVs) } \\
\text { Segment }\end{array}$} & \multicolumn{2}{|c|}{$\mathrm{CSA}\left(\mathrm{mm}^{2}\right)$} & \multirow{2}{*}{$\begin{array}{c}\frac{\text { Right CSA }\left(\mathrm{mm}^{2}\right)}{20^{\circ} \text { contralateral }} \\
\text { rotation }\end{array}$} & \multicolumn{2}{|c|}{ Right CSA $\left(\mathrm{mm}^{2}\right)$} & \multicolumn{3}{|c|}{$\mathrm{CSA}\left(\mathrm{mm}^{2}\right)$} \\
\hline & Right $0^{\circ}$ & Left $0^{\circ}$ & & $0^{\circ}$ & $\begin{array}{l}\text { Max. contralateral } \\
\text { rotation }\end{array}$ & Right and left $0^{\circ}$ & Right $0^{\circ}$ & Left $0^{\circ}$ \\
\hline $\mathrm{J} 1$ (Mean $\pm \mathrm{SD})$ & \multicolumn{2}{|c|}{-} & - & - & - & $17.8 \pm 10.9$ & $48 \pm 30$ & $50 \pm 14$ \\
\hline$J 2($ Mean $\pm S D)$ & $84 \pm 39$ & $65 \pm 31$ & $9.0 \pm 5.6$ & $78 \pm 46$ & $111 \pm 60$ & $10.4 \pm 8.4$ & $37 \pm 31$ & $28 \pm 19$ \\
\hline$J 3($ Mean \pm SD) & \multicolumn{2}{|c|}{-} & - & - & - & $14.8 \pm 13.2$ & $26 \pm 14$ & $21 \pm 11$ \\
\hline $\mathrm{N}$ of IJVs & 45 & 45 & 52 & & 24 & 66 & 10 & 10 \\
\hline Body weight $(\mathrm{kg})($ Mean \pm SD) & \multicolumn{2}{|c|}{-} & $75.3 \pm 15.8$ & \multicolumn{2}{|r|}{-} & \multicolumn{3}{|c|}{-} \\
\hline (range) & \multicolumn{2}{|c|}{-} & - & \multicolumn{2}{|r|}{$63-100.5$} & \multicolumn{3}{|c|}{-} \\
\hline Age (years) (Mean \pm SD) & \multicolumn{2}{|c|}{$36.9 \pm 11.8$} & $37 \pm 11$ & \multicolumn{2}{|r|}{-} & $27.5 \pm 5.0$ & \multicolumn{2}{|c|}{-} \\
\hline (range) & \multicolumn{2}{|c|}{-} & - & \multicolumn{2}{|r|}{$30-86$} & - & \multicolumn{2}{|c|}{$23-42$} \\
\hline Authors & \multicolumn{2}{|c|}{ Kantarci et al. [28] } & Bellazzini et al. [50] & \multicolumn{2}{|r|}{ Suarez et al. [25] } & Zamboni et al. [24] & \multicolumn{2}{|c|}{ Zamboni et al. [20] } \\
\hline Internal Jugular Veins (IJVs) & \multicolumn{8}{|c|}{ AP diameter (mm) } \\
\hline Segment & \multicolumn{2}{|c|}{ Right $0^{\circ}$} & \multicolumn{2}{|l|}{ Right $60^{\circ}$} & \multicolumn{2}{|c|}{ Left $0^{\circ}$} & Left & $60^{\circ}$ \\
\hline$J 2($ Mean \pm SD) & 8.5 & 2.7 & $9.1 \pm 2.8$ & & $7.8=$ & $=2.7$ & $8.2=$ & 2.8 \\
\hline $\mathrm{N}$ of IJVs & & & 100 & & & 100 & & \\
\hline Body weight (kg) (Mean) & & & & & 65.6 & & & \\
\hline (range) & & & & & $32-108$ & & & \\
\hline Age (years) (Mean) & & & & & 55.7 & & & \\
\hline (range) & & & & & $21-89$ & & & \\
\hline Authors & & & & Lorchir & achoonkul et al. [19] & & & \\
\hline
\end{tabular}


which was clearly shown by our study, but the meaning of which will have to be investigated further. This dynamic approach, applied to the conventional static ultrasound screening for CCSVI, allowed us to introduce the first selective criterion for angioplasty. In fact, it would be unthinkable to treat miopragic veins; balloon angioplasty would most likely fail because of the increased distensibility of the venous wall. Obviously, further histochemical studies will be needed to confirm whether jugular collapse, found in MS patients, could be the expression of dysregulation of collagen synthesis.

\section{Additional files}

Additional file 1: SCM stretching manoeuvre. B-mode transverse scan of a normal IJV at J2 level: a slight increase in jugular CSA with contralateral rotation of the head.

Additional file 2: SCM stretching manoeuvre. Color-mode transverse scan of a miopragic IJV at the J2 level: the vein is not clearly visible in the frontal resting position ( $0^{\circ}$ midline) and significantly increases its CSA with the opposite rotation of the head ( $90^{\circ}$ from midline).

Additional file 3: SCM stretching manoeuvre. B-mode longitudinal scan of a hypoplastic IJV at J1 level: there was an imperceptible change in the dimensional values observed during the manoeuvre. The vein has a cylindrical appearance with small longitudinal diameters (3 $\mathrm{mm}$ ).

\section{Abbreviations}

CCSVI: Chronic cerebrospinal venous insufficiency; CSA: Cross-sectional area; ECD: Echo-colour Doppler; HCs: Healthy controls; IJVs: Internal jugular veins; MRV: Magnetic resonance venography; PP: Primary progressive; RR: Relapsing-remitting; SCM: Sternocleidomastoid muscle; SP: Secondary progressive; VD: Valvular defect.

\section{Competing interests}

The authors declare that they have no competing interests.

\section{Authors' contributions}

MF conceived of the study, participated in its design and coordination and primarily drafted the manuscript. EN participated in the design of the study and performed the statistical analysis. RP helped to draft the manuscript. All the authors read and approved the final manuscript.

\section{Acknowledgments}

We thank those who supported our efforts in writing this work: Dr. Sara D'Onofrio and Dr. Leonardo Forzoni (research engineers), as well as Dr. Piero Montesanto (neurobiologist).

\section{Author details}

${ }^{1}$ Phlebolymphology Diseases Centre, Monza Polyclinic, Monza, Italy. ${ }^{2}$ Biostatistics Unit, San Gaudenzio Clinic (Monza Polyclinic Group), Novara, Italy. ${ }^{3}$ Angiology Unit, Villa Cimarosa Medical Centre, Milan, Italy.

Received: 30 June 2013 Accepted: 28 October 2013

Published: 5 November 2013

\section{References}

1. Zamboni P, Galeotti R, Menegatti E, Malagoni AM, Tacconi G, Dall'Ara S, Bartolomei I, Salvi F: Chronic cerebrospinal venous insufficiency in patients with multiple sclerosis. J Neurol Neurosurg Psychiatry 2009, 80(4):392-399.

2. Zamboni P, Consorti G, Galeotti R, Gianesini S, Menegatti E, Tacconi G, Carinci F: Venous collateral circulation of the extracranial cerebrospinal outflow routes. Curr Neurovasc Res 2009, 6(3):204-212.
3. Lee BB, Laredo J, Neville R: Embryological background of truncular venous malformation in the extracranial venous pathways as the cause of chronic cerebrospinal venous insufficiency. Int Angiol 2010, 29(2):95-108.

4. Al-Omari MH, Rousan LA: Internal jugular vein morphology and hemodynamics in patients with multiple sclerosis. Int Angiol 2010, 29(2):115-120.

5. Simka M, Kostecki J, Zaniewski M, Majewski E, Hartel M: Extracranial Doppler sonographic criteria of chronic cerebrospinal venous insufficiency in the patients with multiple sclerosis. Int Angio/ 2010, 29(2):109-114.

6. Zamboni P, Menegatti E, Weinstock-Guttman B, Schirda C, Cox JL, Malagoni AM, Hojnacki D, Kennedy C, Carl E, Dwyer MG, Bergsland N, Galeotti R, Hussein S, Bartolomei I, Salvi F, Ramanathan M, Zivadinov R: CSF dynamics and brain volume in multiple sclerosis are associated with extracranial venous flow anomalies: a pilot study. Int Angiol 2010, 29(2):140-148.

7. Bastianello S, Romani A, Viselner G, Tibaldi EC, Giugni E, Altieri M, Cecconi P, Mendozzi L, Farina M, Mariani D, Galassi A, Quattrini C, Mancini M, Bresciamorra V, Lagace A, McDonald S, Bono G, Bergamaschi R: Chronic cerebrospinal venous insufficiency in multiple sclerosis: clinical correlates from a multicentre study. BMC Neurol 2011, 11:132. 10.1186/1471-2377-11-132.

8. Zaharchuk G, Fischbein NJ, Rosenberg J, Herfkens RJ, Dake MD: Comparison of MR and Contrast Venography of the cervical venous system in Multiple Sclerosis. AJNR Am J Neuroradiol 2011, 32(8):1482-1489.

9. Zivadinov R, Galeotti R, Hojnacki D, Menegatti E, Dwyer MG, Schirda C, Malagoni AM, Marr K, Kennedy C, Bartolomei I, Magnano C, Salvi F, Weinstock-Guttman B, Zamboni P: Value of MR venography for detection of internal jugular vein anomalies in multiple sclerosis: a pilot longitudinal study. AJNR Am J Neurorad 2011, 32(5):938-946.

10. Krogias C, Schröder A, Wiendl H, Hohlfeld R, Gold R: Chronic cerebrospinal venous insufficiency and multiple sclerosis: critical analysis and first observation in an unselected cohort of MS patients. Nervenarzt 2010, 81(6):740-746

11. Mayer CA, Pfeilschiffer W, Lorenz MW, Nedelmann M, Bechmann L, Steinmetz $\mathrm{H}$, Ziemann U: The perfect crime? CCSVI not leaving a trace in MS. J Neurol Neurosurg Psychiatry 2011, 82(4):436-440.

12. Baracchini C, Valdueza JM, Del Sette M, Baltgaile G, Bartels E, Bornstein NM, Klingelhoefer J, Molina C, Niederkorn K, Siebler M, Sturzenegger M, Ringelstein BE, Russell D, Csiba L: CCSVI and MS: a statement from the European Society of neurosonology and cerebral hemodynamics. J Neurol 2012, 259(12):2585-2589.

13. Comi G, Battaglia MA, Bertolotto A, Del Sette M, Ghezzi A, Malferrari G, Salvetti M, Sormani MP, Tesio L, Stolz E, Mancardi G: Italian multicentre observational study of the prevalence of CCSVI in multiple sclerosis (CoSMo study): rationale, design, and methodology. Neurol Sci 2013 34(8):1297-1307.

14. Menegatti E, Genova V, Tessari M, Malagoni AM, Bartolomei I, Zuolo M, Galeotti R, Salvi F, Zamboni P: The reproducibily of colour Doppler in chronic cerebrospinal venous insufficiency associated with multiple sclerosis. Int Angiol 2010, 29(2):121-126.

15. Van den Berg PJ, Visser LH: Extra- and transcranial echo colour Doppler in the diagnosis of chronic cerebrospinal venous insufficiency. Phlebology 2012, 27(Suppl 1):107-113.

16. Dolic K, Marr K, Valnarov V, Dwyer MG, Carl E, Karmon Y, Kennedy C, Brooks C, Kilanowski C, Hunt K, Siddiqui AH, Hojnacki D, WeinstockGuttman B, Zivadinov R: Intra- and extraluminal structural and functional venous anomalies in Multiple Sclerosis, as evidenced by 2 noninvasive imaging techniques. AJNR Am J Neuroradiol 2012 33(1):16-23

17. Zivadinov R, Lopez-Soriano A, Weinstock-Guttman B, Schirda CV, Magnano CR, Dolic K, Kennedy CL, Brooks CL, Reuther JA, Hunt K, Andrews M, Dwyer MG, Hojnacki DW: Use of MR Venography for Characterization of the Extracranial Venous System in Patients with Multiple Sclerosis and Healthy Control Subjects. Radiology 2011, 258(2):562-570

18. Werner JD, Siskin GP, Mandato K, Englander M, Herr A: Review of venous anatomy for venographic interpretation in chronic cerebrospinal venous insufficiency. J Vasc Interv Radiol 2011, 22(12):1681-1690.

19. Lorchirachoonkul T, Ti LK, Manohara S, Lye ST, Tan SA, Shen L, Kang DS: Anatomical variations of the internal jugular vein: implications for successful cannulation and risk of carotid artery puncture. Singapore Med J 2012, 53(5):325-328. 
20. Zamboni P, Sisini F, Menegatti E, Taibi A, Malagoni AM, Morovic S, Gambaccini M: An ultrasound model to calculate the brain blood outflow through collateral vessels: a pilot study. BMC Neurol 2013, 13:81. 10.1186/1471-2377-13-81

21. Mortensen JD, Talbot S, Burkart JA: Cross-sectional internal diameters of human cervical and femoral blood vessels: relationship to subject's sex age, body size. Anat Rec 1990, 226(1):115-124.

22. Escott EJ, Branstetter BF: It's not a cervical lymph node, it's a vein: $\mathrm{CT}$ and MR imaging findings in the veins of the head and neck. Radiographics 2006, 26(5):1501-1515.

23. Jayaraman MV, Boxerman JL, Davis LM, Haas RA, Rogg JM: Incidence of extrinsic compression of the internal jugular vein in unselected patients undergoing CT angiography. AJNR 2012, 33(7):1247-1250.

24. Zamboni P, Menegatti E, Pomidori L, Morovic S, Taibi A, Malagoni AM, Cogo AL, Gambaccini M: Does thoracic pump influence the cerebral venous return? J Appl Physiol 2012, 112(5):904-910.

25. Suarez T, Baerwald JP, Kraus C: Central venous access: the effects of approach, position, and head rotation on internal jugular vein cross-sectional area. Anesth Analg 2002, 95(6):1519-1524.

26. Simka M, Majewski E, Fortuna M, Zaniewski M: Internal jugular vein entrapment in a multiple sclerosis patient. Case Rep Surg 2012. 2012:293568. 10.1155/2012/293568. Epub 2012 Oct 11.

27. Sternberg Z: Autonomic dysfunction: a unifying multiple sclerosis theory, linking chronic cerebrospinal venous insufficiency, vitamin $D(3)$, and Epstein-Barr virus. Autoimmun Rev 2012, 12(2):250-259.

28. Kantarci F, Albayram S, Demirci NO, Esenkaya A, Uluduz D, Uysal O, Saip S, Siva A: Chronic cerebrospinal venous insufficiency: does ultrasound really distinguish multiple sclerosis subjects from healthy controls? Eur Radiol 2012, 22(5):970-979

29. Simka M, Ludyga T, Latacz P, Kazibudzki M: Diagnostic accuracy of current sonographic criteria for the detection of outflow abnormalities in the internal jugular veins. Phlebology 2013, 28(6):285-292.

30. Zaniewski M, Simka M: Biophysics of venous return from the brain from the perspective of the pathophysiology. Rev Recent Clin Trials 2012, 7(2):88-92.

31. Dhulkhed V, Reddy A, Gupta A, Dhulkhed P: An Observational Study Of Change In Diameter Of Right Internal Jugular Vein With Various Body Positions In Volunteers With The Aid Of 2-Dimensional Ultrasonography. Internet J Anesthesiol 2008, 21(2) [http://ispub.com/IJA/21/2/11524]

32. Polman CH, Reingold SC, Banwell B, Clanet M, Cohen JA, Filippi M, Fujihara K, Havrdova E, Hutchinson M, Kappos L, Lublin FD, Montalban X, O'Connor P, Sandberg-Wollheim M, Thompson AJ, Waubant E, Weinshenker B, Wolinsky JS: Diagnostic criteria for multiple sclerosis: 2010 revisions to the McDonald criteria. Ann Neurol 2011, 69(2):292-302. 10.1002/ana.22366.

33. Nicolaides AN, Morovic S, Menegatti E, Viselner G, Zamboni P: Screening for chronic cerebrospinal venous insufficiency (CCSVI) using ultrasound: recommendations for a protocol. Funct Neurol 2011, 26(4):229-248.

34. Mathew JP, Newman MF: Hemodynamic and related monitoring. In Cardiac Anesthesia, Volume 20. 2nd edition. Edited by Estafanour FG, Barasn PG, Rever JG. Philadelphia: Lippincott William and Wilkins; 2005:2-8.

35. Anastasi G, Balboni GC, Motta P: Circulatory system. In Textbook of Human Anatomy, Volume 1. 4th edition. Edited by Ermes. Milan: GEA; 2007:680.

36. Lim CL, Keshava SN, Lea M: Anatomical variations of the internal jugular veins and their relationship to the carotid arteries: a CT evaluation. Australas Radiol 2006, 50(4):314-318.

37. Simka M, Latacz P, Ludyga $T$, Kazibudzki M, Swierad M, Janas $P$, Piegza J: Prevalence of extracranial venous abnormalities: results from a sample of 586 multiple sclerosis patients. Funct Neurol 2011, 26(4):197-203

38. Haacke EM, Feng W, Utriainen D, Trifan G, Wu Z, Latif Z, Katkuri Y, Hewett J, Hubbard D: Patients with multiple sclerosis with structural venous abnormalities on MR imaging exhibit an abnormal flow distribution of the internal jugular veins. J Vasc Interv Radiol 2012, 23(1):60-68.

39. Utrianen D, Feng W, Elias S, Latif Z, Hubbard D, Haacke EM: Using magnetic resonance imaging as a means to study chronic cerebral spinal venous insufficiency in multiple sclerosis patients. Tech Vasc Interv Radiol 2012 15(2):101-112.

40. Lee BB, Bergan J, Gloviczki P, Laredo J, Loose DA, Mattassi R, Parsi K, Villavicencio $J$, Zamboni P: Diagnosis and treatment of venous malformations Consensus Document of the International Union of Phlebology (IUP)-2009. Int Angiol 2009, 28(6):434-451.
41. Coen M, Menegatti E, Salvi F, Mascoli F, Zamboni P, Gabbiani G, Bochaton-Piallat ML: Altered collagen expression in jugular veins in multiple sclerosis. Cardiovasc Pathol 2013, 22(1):33-38.

42. Sansilvestri-Morel P, Rupin A, Badier-Commander C, Kern P, Fabiani JN, Verbeuren TJ, Vanhoutte PM: Imbalance in the synthesis of collagen type I and collagen type III in smooth muscle cells derived from human varicose veins. J Vasc Res 2001, 38:560-568.

43. Haviarova Z, Janega P, Durdik S, Kovac P, Mraz P, Stvrtinova V: Comparison of collagen subtype I and III presence in varicose and non-varicose vein walls. Bratis/ Lek Listy 2008, 109(3):102-105.

44. Rosch R, Klinge U, Si Z, Junge K, Klosterhalfen B, Schumpelick V: A role for the collagen $\mathrm{I} / \mathrm{III}$ and MMP-1/-13 genes in primary inguinal hernia? BMC Med Genet 2002, 3(2). Available from: http://www.ncbi.nlm.nih.gov/pubmed/ 22987234

45. Turba UC, Uflacker R, Hannegan C, Selby JB: Anatomic relationship of the internal jugular vein and the common carotid artery applied to percutaneous transjugular procedures. Cardiovasc Intervent Radiol 2005 28(3):303-306

46. Lensch $\mathrm{E}$, Jost WH: Autonomic disorders in multiple sclerosis. Autoimmune Dis 2011, 2011:803841. 10.4061/2011/803841.

47. Sterman AB, Coyle PK, Panasci DJ, Grimson R: Disseminated abnormalities of cardiovascular autonomic functions in multiple sclerosis. Neurology 1985, 35(11):1665-1668.

48. McDougall AJ, McLeod JG: Autonomic nervous system function in multiple sclerosis. J Neurol Sci 2003, 215(1-2):79-85.

49. Merkelbach S, Dillmann U, Kölmel C, Holz I, Muller M: Cardiovascula autonomic dysregulation and fatigue in multiple sclerosis. Mult Scler 2001, 7(5):320-326.

50. Bellazzini MA, Rankin PM, Gangnon RE, Bjoernsen LP: Ultrasound validation of maneuvers to increase internal jugular vein cross-sectional area and decrease compressibility. Am J Emerg Med 2009, 27(4):454-459. 10.1016/j. ajem.2008.03.034.

51. Bouyssou M, Tricoire J: Experimental detection of a cervical arousal mechanism of yawning, enhancing intracerebral (CSF) fluid pressure. J Dental Res 1985, 64:721.

52. Patra P, Gunness TK, Robert R, Rogez JM, Heloury Y, Le Hur PA, Leborgne J Laude M, Barbin JY: Physiologic variations of the internal jugular vein surface, role of the omohyoid muscle, a preliminary echographic study. Surg Radiol Anat 1988, 10(2):107-112.

53. Rai R, Ranade A, Nayak S, Vadgaonkar R, Mangala P, Krishnamurthy A: A study of anatomical variability of the omohyoid muscle and its clinical relevance. Clinics (Sao Paulo) 2008, 63(4):521-524.

54. Radak D, Tanaskovic S, Antonic Z, Kolar J, Aleksic N, llijevski N: Compressive syndrome of internal jugular veins in multiple sclerosis: does it matter? Phlebology 2012. Available from: http://www.ncbi.nlm.nih.gov/pubmed/ 11872152

doi:10.1186/1471-2377-13-162

Cite this article as: Farina et al: Cross-sectional area variations of internal jugular veins during supine head rotation in multiple sclerosis patients with chronic cerebrospinal venous insufficiency: a prospective diagnostic controlled study with duplex ultrasound investigation. BMC Neurology 2013 13:162.

\section{Submit your next manuscript to BioMed Central and take full advantage of:}

- Convenient online submission

- Thorough peer review

- No space constraints or color figure charges

- Immediate publication on acceptance

- Inclusion in PubMed, CAS, Scopus and Google Scholar

- Research which is freely available for redistribution 